\title{
Detection of B Lines in Patients Presenting with COPD Exacerbation
}

\author{
MOAZ ATEF EL SHAHAT ABDEL ATI, M.D.* and ALSAYED ALI ALMARGHANY, M.D.** \\ The Departments of Chest Diseases* and Caradiology**, Faculty of Medicine, Al-Azhar University, Egypt
}

\begin{abstract}
Background: Diagnosis of cardiogenic pulmonary edema represent a diagnostic difficulty among patients with COPD exacerbation because at many times it could have a similar clinical presentation to other causes of acute COPD exacerbation. Lung ultrasound is an easy and reliable bed side tool that could be helpful for diagnosis of cardiogenic pulmonary edema in COPD patients presented with acute respiratory distress.

Aim of Study: To determine the diagnostic value of what is called B lines which are vertical lines extend from the pleural line to the bottom of the screen in a laser like distribution detected by lung ultrasound performed by the pulmonologist in diagnosis of acute cardiogenic pulmonary edema in COPD patients presented with acute exacerbation.
\end{abstract}

Patients and Methods: A prospective study including fifty two patients was conducted in Chest and Cardiology Departments, Bab-El-Sha'aria and Al-Hussin Hospitals, Al-Azhar University in the period between August 2019 to March 2020. All patients are presented by COPD exacerbation that was attributed to cardiogenic pulmonary edema, echopulmonography using abdominal probein B mode scanning the supra mammary and the infrascapular areas of both lungs was performed for all patients while the patient in setting position.

Results: Among 52 COPD patients with mean age 62.5 \pm 4.6 , including $45(86.5 \%)$ males and $7(13.5 \%)$ was females, according to the FEV1 they was classified as severe COPD in $25(48.1 \%)$ andwith moderate severity in 27 (51. $9 \%$ ) patients, all patients are decompensated by cardiogenic pulmonary edema, BNP was abnormally elevated in all patients, CXR bilateralbat wing infiltration was present in ( $96 \%$ ) and absent in (4\%) of patients. B lines was detected in $88.5 \%$ of all patients with sensitivity of $90.2 \%$ and specificity of $100 \%$.

Conclusion: Echopulmonography performed to evaluate the lung parenchyma for detection of B lines is a simple readily available bedside tool that ishelpful inthe diagnosis of cardiogenic pulmonary edema in patients presented by COPD exacerbation. It could be performed in a short time and comfortable position for the patient who is in respiratory distress with subsequently rapid start of the appropriate management.

Correspondence to: Dr. Moaz Atef El Shahat Abdel Ati, The Department of Chest Diseases, Faculty of Medicine, Al-Azhar University, Egypt
Key Words: COPD-Pulmonary edemaEchopulmonography-B lines.

\section{Introduction}

CHRONIC Obstructive Pulmonary Disease ( COPD) is the third leading cause of death worldwide [1]. Chronic Obstructive Pulmonary Disease ( COPD) patients have about one tofour acute exacerbations every year [2]. In addition, hospital mortality due to Acute Exacerbation of COPD ( AECOPD) is up to $10 \%$ and also the long-term outcome is often poor, with mortality reaching $40 \%$ in the first year [3]. Identifying the underlying etiology is a cornerstone in the management of the patients presented with acute exacerbation of their underlying COPD [4]. Heart failure is a major one of the multiple etiologies that could mimic COPD exacerbation [5]. Clinical evaluation and chest radiography are not always helpful to differentiate between COPD exacerbation and cardiogenic pulmonary edema, the definite diagnosis is still impossible in some cases [6]. The classic clinical findings of crepitations in cardiogenic pulmonary edema and wheezes in patients with COPD is not always the case as the wheezes may be detected in patients with heart failure and crepitations could occur in COPD [7], also up to fifth of patients diagnosed as heart failure have a normal chest radiograph at the time of diagnosis [8]. In the past echopulmonography was considered of little clinical usefulness for assessing different lung pathologies [9] however, since the study by Daniel Lichtenstein in 1997, echopulmonography has become widely used to assess alveolar-interstitial syndrome, which incorporates the pulmonary congestion of underlying cardiac disease [10]. Echopulmonographyis a simple readily available procedure that could be performed by the abdominal probe, it needs less training than echocardiography and could be performed by non sonographer in contrast to echocardiography that is often nerformed onlv hv snecial- 
ists, it has shown better accuracy than clinical evaluation and chest radiograph for the identification of pulmonary congestion, even when performed by non sonographer [11].

\section{Aim of the study:}

To determine the sensitivityand specificity of echopulmonography performed by the pulmonologist using the abdominal probe in diagnosis of cardiogenic pulmonary edema as a cause of acute respiratory decompensation in patients with underlying COPD.

\section{Patients and Methods}

This study was conducted in the Chest and Cardiology Departments Al-Azhar University Hospitals (Al-Hussein and Bab Al-Sharia) and include fifty two patients presented with COPD exacerbation that was attributed to cardiogenic pulmonary edema.

\section{All patients were subjected to the}

following: - Clinical history and

examination.

- Routine laboratory tests (CBC, liver and renal functions) and Brain Natriuretic Peptide (BNP).

- CXR, spirometry, ABG and

echocardiography. - Echopulmonography.

\section{Exclusion criteria include:}

Patients with any other cause of acute exacerbation including those with infective exacerbation, pneumonia, pneumothorax and pulmonary embolism.

Patients with pulmonary comorbidities other than COPD such as interstitial lung disease.

Procedure: Echopulmonography was performed in all patients in the setting position using the abdominal curved probe held in a vertical position parallel to the midline scanning both the supramammary area from the midline to the anterior axillary line and the infrascapular area from the midline to the posterior axillary line bilaterally with depth adjusted at $8 \mathrm{~cm}$ and frequency of $5 \mathrm{mHZ}$ in B mode in a time not exceeding few minutes aiming to detect the B lines which are defined as a multiple hyperechoic vertical lines that is confluent and extend without fading from the pleural line to bottom of the screen.

\section{Statistical analysis of data:}

Statistical analysis was carried out using the SPSS computer package version 25.0 (IBM SPSS

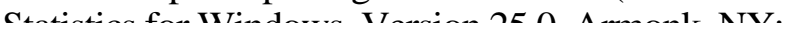

IBM Corp., USA). For descriptive statistics: The mean \pm SD was used for quantitative variables while the number and percentage were used for qualitative variables. For analytic statistics: Fisher's Exact test or Chi-square test were used to assess the differences in frequency of qualitative variables while Mann-Whitney U-test was applied to assess the differences in means of non-parametric quantitative variables. The statistical methods were verified, assuming a significant level of $p<0.05$ and a highly significant level of $p<0.001$.

\section{Results}

Table (1): Generalcharacteristics of the studied population.

\begin{tabular}{|c|c|c|}
\hline \multirow{2}{*}{ Variables } & \multicolumn{2}{|c|}{ Group $(n=52)$} \\
\hline & No & $\%$ \\
\hline Age (year): & \multicolumn{2}{|c|}{$62.5 \pm 4.6$} \\
\hline Mean \pm SD & \multirow{2}{*}{\multicolumn{2}{|c|}{$52-70$}} \\
\hline Min - max & & \\
\hline \multicolumn{3}{|l|}{ Sex: } \\
\hline Male & 45 & 86.5 \\
\hline Female & 7 & 13.5 \\
\hline
\end{tabular}

Table (2): Severity of COPD among the studied population.

\begin{tabular}{lll}
\hline \multirow{2}{*}{ Variables } & \multicolumn{2}{c}{ Group $(\mathrm{n}=52)$} \\
\cline { 2 - 3 } & No & $\%$ \\
\hline COPD severity: & & \\
Severe & 25 & 48.1 \\
Moderate & 27 & 51.9 \\
\hline
\end{tabular}

Table (3): Detection of B lines.

\begin{tabular}{ccc}
\hline B lines & $\mathrm{n}=52$ & $\%$ \\
\hline Present & 46 & 88.5 \\
Absent & 6 & 11.5 \\
\hline
\end{tabular}

Table (4): Relation of B lines with COPD severity.

\begin{tabular}{|c|c|c|c|}
\hline \multirow{3}{*}{ B lines } & \multicolumn{2}{|c|}{ COPD severity } & \multirow{3}{*}{$\begin{array}{c}p- \\
\text { value }\end{array}$} \\
\hline & Moderate & Severe & \\
\hline & $\mathrm{N}=27(\%)$ & $\mathrm{n}=25(\%)$ & \\
\hline Present & $25(92.6)$ & $21(84.0)$ & 0.411 \\
\hline Absent & $2 \quad(7.4)$ & (16.0) & \\
\hline
\end{tabular}

Table (5): Relation of B lines with bilateral infiltration by CXR.

\begin{tabular}{cccc}
\hline & \multicolumn{2}{c}{ Bilateral infiltration by CXR } & \\
\cline { 2 - 3 } B lines & Present & Absent & \\
\hline Present & 46 & 0 & 46 \\
Absent & 5 & 1 & 6 \\
\hline Total & 51 & 1 & 52 \\
\hline
\end{tabular}




\section{Discussion}

This study include fifty two patients with age ranged from (52-70) years and mean age of (62.5 \pm 4.6) (Table 1), there was [ 45 males $(86.5 \%)$ and 7 females (13.5\%)] (Table 1) all of them have suffering from COPD which was severe in 25 ( $48.1 \%$ ) patients and of moderate severity in 27 ( $51.9 \%$ ) classified according to the percentage of $\mathrm{FEV}_{1}$ [12] (Table 2), all patients aredecompensated by acute cardiogenic pulmonary edema.

All patients were presented by acute respiratory distress and diagnosed as acute cardiogenic pulmonary edema based on clinical evaluation, bilateral infiltration of bat wing appearance in chest $\mathrm{X}$-ray, an abnormally elevated BNB, echocardiographic assessment and the proper response to the appropriate medication.

All patients were examined with echopulmonography while in the sitting position which is more comfortable for the patients with acute cardiogenic pulmonary edema in contrast to echocardiography that should be performed in lying position particularly in hyperinflated patients where the epigastric window is more evident, a clearly uncomfortable and even more distressing for the COPD patient with acute deterioration.

The echopulmonographic evidence of cardiogenic pulmonary edema was based on the detection of multiple confluent B lines in more than one lung zone of each lung, in this study it was the bilateral supramammary and the bilateral infrascapular areas simultaneously at the time of examination. B lines are defined as a hyperechoicreverberation artifacts that result from excess extravascular lung water due to contact of air and water, a two media with different acoustic impedance [13], B lines are considered pathological for cardiogenic pulmonary edema when multiple confluent B lines are detected in more than one lung zone of each lung, they are also known as a comet tail or lung rockets that extend from the pleural line to the bottom of the screen without fading in a laser like distribution [14].

In the present study the $\mathrm{B}$ lines was detected in 46 out of 52 COPD patients (Table 3) who are diagnosed with cardiogenic pulmonary edema with sensitivity of $90.2 \%$ and specificity of $100 \%$ when compared to chest radiograph (Table 5) and this is in agreement with the study conducted by Lichtenstein [15] who was the first one to determine the association between diffuse pulmonary interstitial infiltration and the detection of multiple bilateral B-lines by lung US scan when the authors examined a critically ill population $(\mathrm{n}=250)$ and compared lung US for B-lines with the radiological diagnoses ( chest radiography and CT scan) B-lines showed high accuracy with sensitivity of $93.4 \%$ and specificity of $93 \%$, but in Lichtenstein D study the patients with underlying lung diseases like pneumonia and interstitial lung disease were not excluded and there was no specification for the type of the patients in clear contrast to the current study which only address COPD exacerbation patients and exclude any patient with underlying lung comorbidities.

In the study performed by Lichtenstein $\mathrm{D}$ and Mezière $G$ [16] the diagnosis of diffuse sonographic alveolar-interstitial syndrome allows detection of pulmonary edema with a sensitivity of $100 \%$ and specificity of $92 \%$.

Another study performed by [17] in the emergency department and showed sensitivity of $85.7 \%$ and specificity of $97.7 \%$ of B lines in the diagnosis of cardiogenic pulmonary edemaand this is in agreement with the current study.

In a recent study accomplished by [18] they conclude that lung ultrasound was found to have a high specificity (94.4\%) and sensitivity (100\%) for the correct identification of alveolar interstitial syndrome using B lines.

In the current study all patients were suffering from COPD and because of the fact of air trapping that characterize the COPD, B lines may be unobtainable in some patients.

Regarding the severity of COPD (Table 2) there was $25(48.1 \%)$ patients with severe COPD among them B lines was detected in $21(84.0 \%)$ patients and absent in $4(16 \%)$ patients (Table 4$)$, while in $27(51.9 \%)$ of patients with moderate COPD (Table 2) the B lines was present in $25(92.6 \%)$ and absent in two $(7.4 \%)$ patients (Table 4 ) with no statistically significant difference in detection of B lines according to the severity of COPD.

Limitations of this study include the small sample of patients and the fact that different classes of COPD severity according to FEV1 were not included in this study including those with mild and very severe COPD, also further studies are needed to assess COPD patients with predominant emphysema where significant hyperinflation and air trapping is present, to answer if the lung ultrasound is still useful for detection of B lines in the context of cardiogenic pulmonary edema even in those patients with excess air in their lungs. 


\section{References}

1- CHRISTIAN VINIOL and CLAUS F. VOGELMEIER: Exacerbations of COPD European Respiratory Review 27: 170103, 2018.

2- J.J. SOLER-CATALUÑA, M.Á. MARTÍNEZ-GARCÍA, P. ROMÁN SÁNCHEZ, E. SALCEDO, M. NAVARRO and R. OCHANDO: Severe acute exacerbations and mortality in patients with chronic obstructive pulmonary disease, 2005.

3- RAMSEY S. and SULLIVAN S.: Economic burden of acute exacerbations of chronic obstructive pulmonarydisease. In: Siafakas NM, Anthonisen NR, Georgopoulos D, eds. Management of AcuteExacerbation of COPD. New York, Marcel Dekker Inc., pp. 19-27, 2004.

4- CELLI B.R., MACNEE W. and ATS/ERS TASK FORCE.: Standards for the diagnosis and treatment of patients with COPD: A summary of the ATS/ERS position paper. Eur. Respir. J., 23: 932-46, 2004.

5- MacNEE W.: Pathophysiology of acute exacerbations of chronic obstructive pulmonary disease. In: Siafakas NM, Anthonisen NR, Georgopoulos D, eds.Management of Acute Exacerbation ofCOPD. New York, Marcel Dekker Inc., pp. 29-46, 2004.

6- LUCIANO CARDINALE, ADRIANO MASSIMILIANO PRIOLA, FEDERICA MORETTI and GIOVANNI VOLPICELLI: World J. Radiol. Effectiveness of chest radiography, lung ultrasound and thoracic computed tomography in the diagnosis of congestive heart failure, 2014.

7- ZENG Q. and JIANG S.: Update in diagnosis and therapy of coexistent chronic obstructive pulmonary disease and chronic heart failure. J. Thoracic. Dis., 4 (3): 310-5, 2012.

8- COLLINS S.P., LINDSELL C.J., STORROW A.B. and ABRAHAM W.T.: Prevalence of negative chest radiography results in the Emergency Department patient with decompensated heart failure. Ann. Emerg. Med., 47 (1): 13-8, 2006.

9- LEIDI F., CASELLA F. and COGLIATI C.: Bedside lung ultrasound in the evaluation of acute decompensated heart
10- LICHTENSTEIN D., MÉZIÈRE G., BIDERMAN P., GEPNER A. and BARRÉ O.: The comet-tail artifact, an ultrasound sign of alveolar-interstitial syndrome. Am. J. Respir. Crit. Care Med., 156 (5): 1640-6, 1997.

11- CHIEM A.T., CHAN C.H., ANDER D.S., KOBYLIVKER A.N. and MANSON W.C.: Comparison of expert and novice sonographers' performance in focused lung ultrasonography in dyspnea (FLUID) to diagnose patients with acute heart failure syndrome. Acad. Emerg. Med., 22 (5): 564-73, 2015.

12- Global Initiative for Chronic Obstructive Pulmonary Disease (GOLD), 2019.

13- LICHTENSTEIN D.A., MEZIÈRE G., LASCOLS N., BIDERMAN P., COURRET J.P., GEPNER A., GOLDSTEIN I. and TENOUDJI-COHEN M.: Ultrasound diagnosis of occult pneumothorax. Crit. Care Med., 33: 12318, 2005.

14- LICHTENSTEIN D.A.: Ultrasound in the management of thoracic disease. Crit. Care Med., 35: S250-S261, 2007.

15- LICHTENSTEIN D., MÉZIÈRE G., BIDERMAN P., GEPNER A. and BARRÉ O.: The comet-tail artifact, an ultrasound sign of alveolar-interstitial syndrome. Am. J. Respir Crit. Care Med., 156 (5): 1640-6, 1997.

16- LICHTENSTEIN D. and MEZIÈRE G.: A lung ultrasound sign allowing bedside distinction between pulmonary edema and COPD: The comet tail artifact. Intensive Care Med., 24: 1331-4, 1998.

17- VOLPICELLI G., MUSSA A., GAROFALO G., CARDINALE L., CASOLI G., PEROTTO F., FAVA C. and FRASCISCO M.: Bedside lung ultrasound in the assessment of alveolar-interstitial syndrome. Am. J. Emerg. Med., 24: 689-96, 2006.

18- MIRKO ZANATTA, PIERO BENATO, SIGILFREDO De BATTISTI, CONCETTA PIROZZI, RENATO IPPOLITO and VITO CIANCI: Pre-hospital lung ultrasound for cardiac heart failure and COPD: Is it worthwhile? Critical Ultrasound Journal volume 10, Article number: กา กา1 


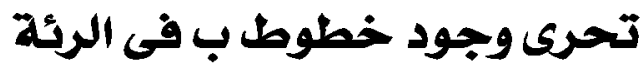

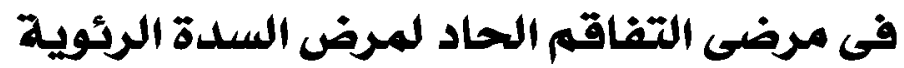

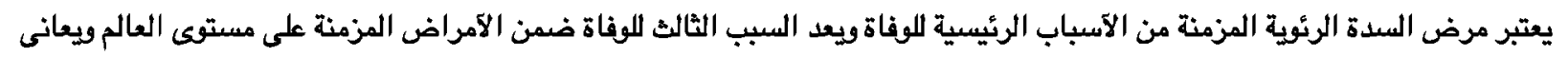

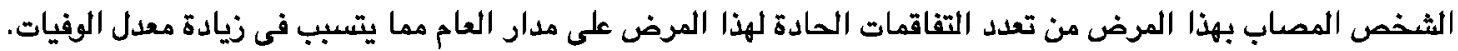

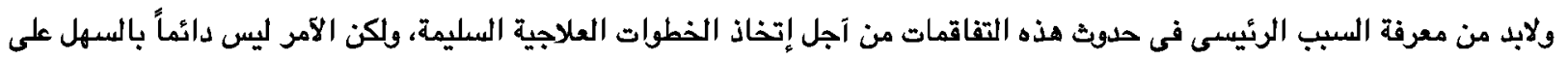

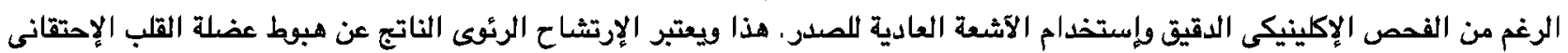

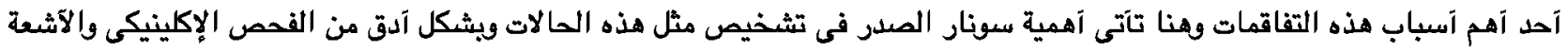

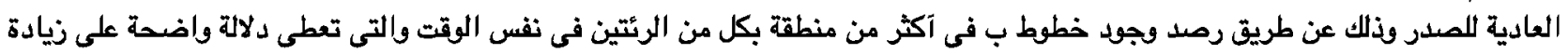

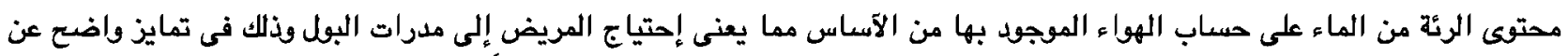

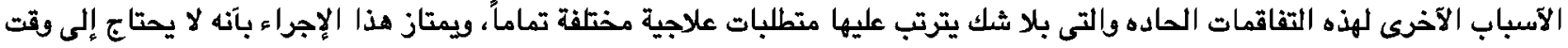

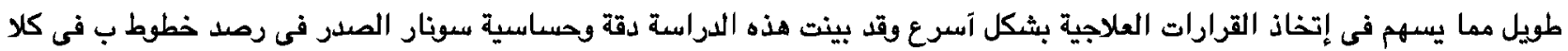

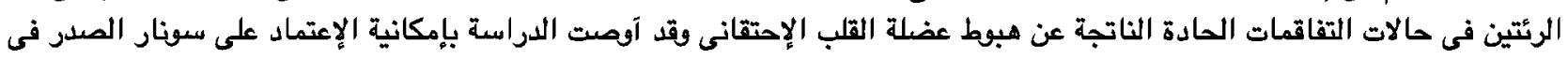

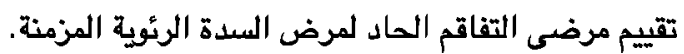

